\title{
Aplicação do sistema UASB-lagoas de polimento para o tratamento de esgoto visando ao reúso agrícola ou industrial ou à proteção de recursos hídricos
}

\section{Application of the UASB-polishing pond system for sewage tratment aiming at agricultural or industrial reuse or at protection of water resources}

Data de entrada: $18 / 06 / 2020$

Data de aprovação: $10 / 11 / 2020$

Adrianus van Haandel ${ }^{1 *} \mid$ Silvânia Lucas dos Santos ${ }^{2} \mid$ Francisco Vieira Paiva ${ }^{3}$

DOI: https://doi.org/10.36659/dae.2021.027

ORCID ID

Haandel A (D) https://orcid.org/0000-0002-9937-6715
Santos SL (D) https://orcid.org/0000-0002-6905-3966

Paiva FV (iD https://orcid.org/0000-0002-7419-3242

\section{Resumo}

No presente trabalho comparam-se diferentes sistemas que são usados para tratar esgoto, visando ao reúso agrícola ou industrial ou ainda à descarga em água de superfície. $O$ tipo de sistema de tratamento deve atender aos requisitos necessários ao uso que se prevê para o efluente. Distinguem-se assim quatro tipos de sistemas de tratamento: lodo ativado, reator UASB, lagoas de estabilização e a combinação UASB-Lagoa de polimento (LP). O reator UASB sozinho não produz uma qualidade de efluente que permita o reúso ou descarga em águas de superfície. Se o reúso agrícola é desejado, não há necessidade de remoção de nutrientes. Nesse caso, os sistemas de lagoas de estabilização e UASB-LP podem ser usados. Se o reúso industrial é previsto, a remoção de nutrientes é necessária e pode-se usar o sistema de lodo ativado ou UASB-LP. Na escolha racional do tipo de sistema de tratamento, os fatores mais importantes são: desempenho e a área necessária. Pelo desempenho do sistema, avalia-se a capacidade de produzir a qualidade do efluente desejado e a área necessária indica se é factível a implantação do sistema. Outros fatores, como custo, simplicidade e estabilidade operacional também são relevantes. Ao fazer a comparação foi observado que o sistema com a melhor qualidade do efluente é UASB-LP, mas a área necessária é relativamente grande. $O$ lodo ativado produz um efluente com qualidade muito boa, contudo o custo é alto, a operação não é simples e instabilidades podem ocorrer. $\mathrm{O}$ sistema de lagoas de estabilização deve ser evitado, porque é inferior ao UASB-LP em vários aspectos.

Palavras-chave: Sistemas de tratamento de esgoto. Reúso agrícola. Reúso industrial. Lodo ativado. UASB. Lagoa de estabilização. UASB + lagoas de polimento.

\section{Abstract}

In this paper, different systems for sewage treatment are compared, aiming to reuse the effluent in agriculture or industry or discharge into surface water. The type of treatment system must match the intended use of the effluent. There are four types of treatment systems: activated sludge, UASB reactor, stabilization pond and the combination

\footnotetext{
${ }^{1}$ Universidade Federal de Campina Grande - UFCG - Paraíba - Brasil.

${ }^{2}$ Universidade Federal do Rio Grande do Norte - UFRN - Natal - Rio Grande do Norte - Brasil.

${ }^{3}$ Universidade de Fortaleza - Unifor - Fortaleza - Ceará - Brasil.

* Autor correspondente: adrianusvhagmail.com.
} 
$U A S B+$ polishing pond (LP). The UASB reactor alone does not produce an effluent quality that allows reuse or discharge into surface waters. If agricultural reuse is foreseen, there is no need to remove nutrients. In this case, the stabilization pond and UASB-LP systems are suitable, if area is available. If industrial reuse is foreseen, removal of nutrients is necessary and activated sludge or UASP-LP can be used. Regarding the rational selection of the type of treatment system, the most important factors are performance and the required area. Based on the performance of the system, it is assessed whether the system is capable of producing the desired effluent quality and the required area indicates whether the system is feasible. Other factors such as cost, simplicity and operational stability are also important. The system with the best quality of the effluent is UASB-LP, but the required area is relatively large. Activated sludge produces very good quality of the effluent but the cost is high, the operation is not simple and instability can occur. The stabilization pond system should be avoided, as it is very inferior to UASB-LP in every aspect. Keywords: Sewage treatment systems. Agricultural reuse. Industrial reuse. Activated sludge. UASB. Stabilizations ponds. UASB + polishing ponds.

\section{INTRODUÇÃO}

Há basicamente quatro alternativas para o uso do efluente de sistemas de tratamento de esgoto: (1) reúso agrícola; (2) reúso urbano, (3) reúso industrial e (4) descarga em águas de superfície. A qualidade desejável para o efluente é diferente para as quatro alternativas: enquanto no caso de reúso agrícola a remoção de nutrientes não é necessária e até mesmo contraprodutiva, para o reúso industrial e descarga em águas de superfície a remoção de nutrientes é de vital importância. Reúso urbano requer um efluente com poucos sólidos em suspensão e boa qualidade higiênica. A remoção de nutrientes tem grande repercussão sobre o tipo e o tamanho do sistema de tratamento a ser aplicado. Por essa razão, é necessário que no estágio de planejamento se defina como será a disposição final do efluente. Além da qualidade desejada do efluente, há outros aspectos de fundamental importância na decisão de qual é o sistema de tratamento mais adequado numa determinada situação de projeto, como a área disponível, o custo de construção e de operação, bem como a simplicidade de construção e de operação.

Na prática de tratamento de esgoto há três tipos de sistemas que têm ampla aplicação: (1) sistemas aeróbios, como lodo ativado e suas varian- tes; (2) sistemas anaeróbios, com predominância do reator UASB; e (3) sistemas mistos, no qual se enquadram as lagoas de estabilização. No presente trabalho se introduz uma quarta alternativa: a combinação do reator UASB com lagoas como unidades de pós-tratamento, as assim denominadas lagoas de polimento (LP), sendo que essas lagoas são operadas em regime de bateladas sequenciais (BS): (UASB-LPBS). Embora o funcionamento dos tipos de sistemas de tratamento se baseie na aplicação de microrganismos, eles exibem grandes diferenças entre si, tanto no princípio de funcionamento como nos objetivos de tratamento e no tamanho.

O aspecto primordial na escolha do sistema de tratamento de esgoto é a legislação ambiental. No caso do Brasil, a qualidade do efluente deve estar de acordo com os padrões de qualidade exigidos pelas Resoluções 357/2005 e 430/2011 do Conselho Nacional do Meio Ambiente - Conama (BRASIL, 2005 e 2011). Em adição às normas especificadas pelo Conama pode haver outras de autoridades estaduais e municipais, sendo que estas tendem a ser mais restritivas.

Outro fator de grande importância na escolha do tipo de tratamento mais adequado é o tamanho da população a ser servida. A área ocupada varia entre um mínimo de 0,01 e um máximo de 
$3 \mathrm{~m}^{2}$ /Eh (equivalente de habitante) para reatores UASB e lagoas de estabilização, respectivamente. Em cidades grandes, a área a ser ocupada pelo sistema de tratamento é limitada e cara, de modo que geralmente as lagoas não podem ser aplicadas. Em cidades pequenas, a disponibilidade de área é maior e de menor custo, o que torna mais viável a aplicação de lagoas.

Embora o tratamento adequado de esgoto seja de vital importância para a saúde pública e para a proteção dos recursos hídricos, o custo da implantação da infraestrutura de saneamento básico é tão elevado que normalmente o governo federal financia parte ou a totalidade dos recursos para sua implantação. $O$ custo per capita da coleta de tratamento depende do tamanho da população a ser servida, da topografia, da área a ser utilizada para o sistema de tratamento, das condições climáticas prevalecentes e da natureza do sistema de tratamento. $O$ tipo de tratamento e o sistema de coleta são interrelacionados: enquanto há sistemas que devem ser construídos longe da aglomeração urbana por causa do incômodo que causam (odores), outros podem ser construídos pertos ou mesmo dentro dos centros e pode ter mais de um sistema numa cidade, o que pode diminuir enormemente os custos. Não são raros os exemplos em que a segmentação da rede de coleta mais os custos de estações de tratamento para cada segmento é menor que somente a rede unitária de coleta sem o sistema de tratamento.

Para avaliar a qualidade de um projeto de saneamento básico devem-se considerar os custos de implantação da rede de coleta e da estação de tratamento de esgoto (ETE). Outros fatores, como a saúde pública e a proteção dos recursos hídricos, são igualmente ou mais importantes do que os fatores técnicos. Deve-se ainda considerar o valor do efluente produzido como resultado do tratamento de esgoto. A água nova que se obtém como resultado da coleta e do tratamento de esgoto em si pode ter um grande valor quando se aplica reúso na agricultura ou na indústria. Se a destinação final do efluente for o reúso agrícola ou o reúso urbano para atividades menos nobres, como jardinagem ou lavagens de ruas, os objetivos do tratamento serão a redução da concentração de material orgânico e de patógenos. Se a destinação for reúso na indústria ou descarga em águas de superfície, será necessário também reduzir as concentrações de nutrientes. Em regiões áridas, o reúso pode ser de grande utilidade para estimular as atividades agrícolas ou industriais.

\section{REÚSO DE EFLUENTE DE SISTEMAS}

\section{DE TRATAMENTO}

O reúso de esgoto tratado, como fonte alternativa de água, pode trazer benefícios econômicos, sociais e ambientais significativos, particularmente em regiões com parcos recursos hídricos, que são os principais motivadores para sua implementação. Os principais benefícios socioeconômicos são (USEPA, 2016):

- Aumento dos recursos hídricos disponíveis e consequentemente redução de uso de águas de superfície e subterrânea;

- Redução do consumo de energia comparado com recursos hídricos como dessalinização e transporte de água sobre longa distância;

- Redução de cargas de nutrientes lançada em corpos receptores, o que tende a diminuir a eutrofização do corpo receptor do efluente;

- Aumento da produção agrícola;

- Aumento da viabilidade de desenvolvimento industrial em regiões áridas, onde outras fontes de recursos hídricos não estão disponíveis ou são caras;

- Possibilidade de uso de esgoto tratado para abastecimento público. 
$\mathrm{Na}$ Tabela 1 apresentam-se os constituintes indesejáveis presentes no esgoto, os problemas que causam e os mecanismos para sua remoção. O tratamento primário, a sedimentação de sólidos suspensos (SS), é incompleto e não é mais aplicado em sistemas comunitários. 0 tratamento secundário visa remover o material orgânico (MO), e se for aplicado junto com a remoção de patógenos é um tratamento adequado para o reúso agrícola. A remoção do $\mathrm{MO}$ se dá tanto em ambiente aeróbio (oxidação para $\mathrm{CO}_{2}$ e $\mathrm{H}_{2} \mathrm{O}$ ) como em ambiente anaeróbio (digestão para $\mathrm{CH}_{4}$ e $\mathrm{CO}_{2}$ ). Os nutrientes que não são removidos são usados produtivamente como fertilizante na irrigação, substituindo parte dos fertilizantes necessários para uma boa produção. 0 tratamento terciário visa à remoção dos nutrientes nitrogênio e fósforo. $\mathrm{O}$ nitrogênio é removido pelos processos sequenciais de nitrificação (oxidação biológica de amônia para nitrato) e desnitrificação (redução de nitrato para nitrogênio molecular). Os mecanismos de remoção de patógenos são diferentes para ovos de helmintos $(\mathrm{OH})$ e para Coliformes Termotolerantes (CTT). A remoção de $\mathrm{OH}$ se dá pela sedimentação junto ao lodo, nos sistemas de tratamento, se o tempo de permanência for suficiente. Na remoção de CTT pode-se usar o tempo, se este for suficiente, ou métodos químicos (adição de desinfetantes, cloro ou ozônio) ou físicos (aplicação de luz ultravioleta).

Há diferentes formas de reúso, e para cada forma de reúso há exigências da concentração máxima dos constituintes indesejáveis no esgoto. $\mathrm{Na} \mathrm{Ta}-$ bela 2 observam-se as formas de reúso que são aplicadas na prática, e mostram-se as exigências que se faz com respeito a remoção dos constituintes indesejáveis. A Tabela 2 mostra ainda que a remoção de SS e MO é importante em todos os sistemas de tratamento. A Fig. 1 mostra esquematicamente os três tipos de sistemas de tratamento que tradicionalmente são mais amplamente empregados para este fim. Também se apresentam suas vantagens e desvantagens.

Tabela 1 - Constituintes indesejáveis normalmente encontrados em esgoto municipal.

\begin{tabular}{|c|c|c|}
\hline Constituinte indesejável & Problemas que causa & Soluções \\
\hline $\begin{array}{l}\text { Sólidos Suspensos } \\
\text { (SS) }\end{array}$ & Assoreamento de rios e lagos & $\begin{array}{c}\text { Tratamento primário: separação dos sólidos } \\
\text { sedimentáveis }\end{array}$ \\
\hline $\begin{array}{l}\text { Material Orgânico } \\
\text { (MO) }\end{array}$ & Consumo de oxigênio no corpo receptor & $\begin{array}{l}\text { Tratamento secundário: uso de microrganismos } \\
\text { para metabolizar o MO }\end{array}$ \\
\hline $\begin{array}{l}\text { Nutrientes } \\
\quad(N, P)\end{array}$ & $\begin{array}{l}\text { Eutrofização: crescimento de algas } \\
\text { no corpo receptor }\end{array}$ & $\begin{array}{c}\text { Tratamento terciário: } \\
\text { N- Nitrificação/Desnitrificação } \\
\text { P-Incorporação no lodo }\end{array}$ \\
\hline $\begin{array}{c}\text { Patógenos } \\
\text { Ovos de helmintos }(\mathrm{OH}) \\
\text { Coliformes Termotolerantes (CTT) }\end{array}$ & Contaminação: doenças em humanos e animais & $\begin{array}{l}\text { OH: floculação no lodo/Sedimentação, } \\
\text { CTT: biológico (tempo), químico }\left(\mathrm{CL}_{2}, \mathrm{O}_{3}\right) \text {, físico (UV) }\end{array}$ \\
\hline
\end{tabular}

Tabela 2 - Importância da remoção de constituintes indesejáveis no esgoto para diferentes formas de reúso.

\begin{tabular}{|c|l|c|c|c|c|}
\hline Aplicação & \multicolumn{1}{|c|}{ SS } & Mo & N \& $\mathbf{P}$ & \multicolumn{1}{|c|}{ Matógenos } \\
\hline Agrícolas & Muito importante & Importante & Desnecessário & Muito importante \\
\hline Industriais & Muito importante & Muito importante & Muito importante & Muito importante & P/ Aplicações especiais \\
\hline Urbanas & Muito importante & Muito importante & Desnecessário & Muito importante \\
\hline Recreativas & Muito importante & Muito importante & Importante & Muito importante \\
\hline Ambientais & Muito importante & Muito importante & Muito importante & Muito importante \\
\hline Abastecimentessário & Desnecessário \\
\hline & Muito importante & Muito importante & Muito importante & Muito importante \\
\hline
\end{tabular}




\section{TIPOS DE SISTEMAS PARA}

\section{TRATAMENTO DE ESGOTO}

\subsection{Lodo ativado}

O sistema de lodo ativado é aeróbio, sendo que o oxigênio é transferido da atmosfera para a fase líquida (o licor misto) por meio de aeração mecânica. Existem duas variantes do sistema, sendo que em uma, operando com fluxo contínuo, há vários reatores em série onde se realizam os diferentes processos de tratamento, seguido por um decantador. Na outra variante, o sistema é operado em regime de bateladas sequenciais com um único reator onde todos os processos (inclusive a separação sólido-líquido) se desenvolvem sequencialmente. Os sistemas de lodo ativado têm como pontos positivos o seu bom desempenho na remoção de todos os constituintes indesejáveis ( $M O$, patógenos, nitrogênio e fósforo) e ocupam uma área reduzida. Todavia, o sistema também apresenta desvantagens: o custo tanto de construção como de operação é bem mais elevado do que de outros sistemas, a operação não é simples e requer a presença de pessoal qualificado. Por essas razões, o sistema de lodo ativado é indicado para grandes centros urbanos, onde a área disponível é um problema.
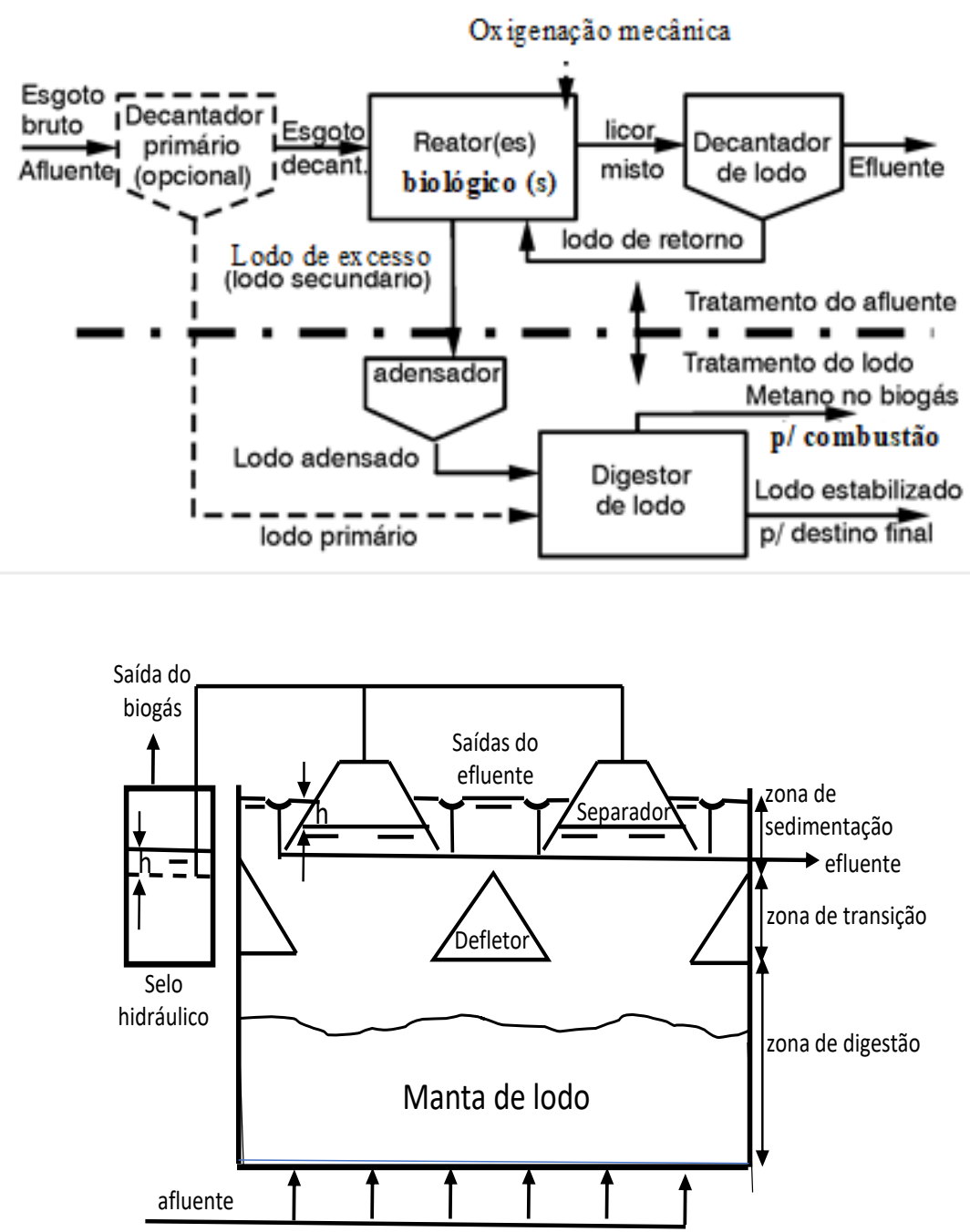

Sistema de lodo ativado

Vantagens

- Remoção de SS e MO eficiente.

- Remoção de N \& P factível.

- Área reduzida.

\section{Desvantagens}

- Aeróbio: consumo de energia.

- Alta produção de lodo.

- Alto custo construção e operação.

- Operação requer pessoal qualificado.

- Instabilidade operacional ocorre.

Figura 1 - Representação dos três tipos de tratamento biológicos mais aplicados na prática. Fonte: Van Haandel e van der Lubbe, 2019; van Haandel e Marais, 1999. 
Figura 1 - Continuação...

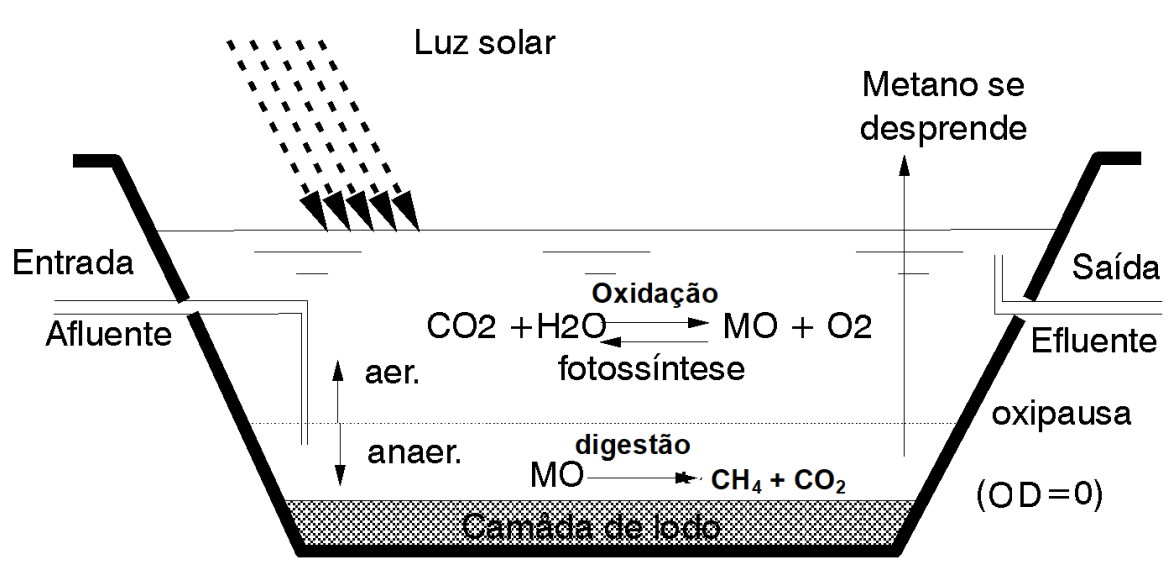

Sistemas mistos:

Lagoa de estabilização

Vantagens

- Simples construção e operação.

- Custo baixo de operação.

- Custo baixo de construção.

Desvantagens

- Área grande: evaporação

de água.

- Sem remoção de N\&P.

- Libera maus odores.

- Emissário longo com custo elevado.

- Impopular pela alta

visibilidade sistema.

A boa qualidade do efluente possibilita o reúso não somente para fins agrícolas, mas também como água de utilidades para a indústria. Nos Estados Unidos já existem plantas de tratamento em operação que produzem água de reúso para o abastecimento humano, sendo que neste caso processos de tratamento avançado são necessários - podendo ser citados, entre eles, a osmose reversa e a biofiltração em ozônio, entre outras e aplicados para remover eventuais contaminantes residuais e corrigir a matriz iônica da água antes de sua distribuição.

\subsection{Reator UASB}

O reator UASB não tem as desvantagens associadas ao sistema de lodo ativado, mas a qualidade do seu efluente é inferior e não é compatível com as diretrizes do Conama nos seus aspectos fundamentais. Portanto, haverá necessidade da aplicação de pós-tratamento para que o efluente obtenha características que permitam o reúso ou a descarga em águas superficiais. Todavia, as vantagens do reator UASB são consideráveis: grande parte do $\mathrm{MO}$ e dos SS (inclusive coloídes) é removida sem que haja necessidade de aplicar energia ou outros insumos. Santos, Chaves e van Haandel (2018) pesquisaram a influência da temperatura sobre a eficiência de remoção do MO em reatores UASB e chegaram a duas conclusões importantes:

(1) A idade de lodo é a variável operacional básica do reator UASB. Para uma eficiência máxima de remoção de $\mathrm{MO}$, a idade de lodo deve ter um valor de $100 \mathrm{~d}$, aproximadamente, independentemente da temperatura. A Fig. 2 mostra a relação entre a idade de lodo e a eficiência de remoção do MO para diferentes temperaturas. Há uma clara relação entre a temperatura e a eficiência máxima. No Brasil, a temperatura mínima do esgoto é em torno de $16^{\circ} \mathrm{C}$. A Fig. 2 mostra que para essa temperatura a eficiência máxima é em torno de $55 \%$. Para uma temperatura no esgoto de $30^{\circ} \mathrm{C}$ (a máxima no Brasil), a eficiência máxima é em torno de $75 \%$.

(2) O tempo de permanência para a eficiência máxima da digestão anaeróbia depende da temperatura, como indica a Fig. 3, que mostra a relação empírica estabelecida por Santos, Chaves e van Haandel (2018), bem como a relação definida na norma Brasileira NBR 12.209/2011 (ABNT, 2011). 


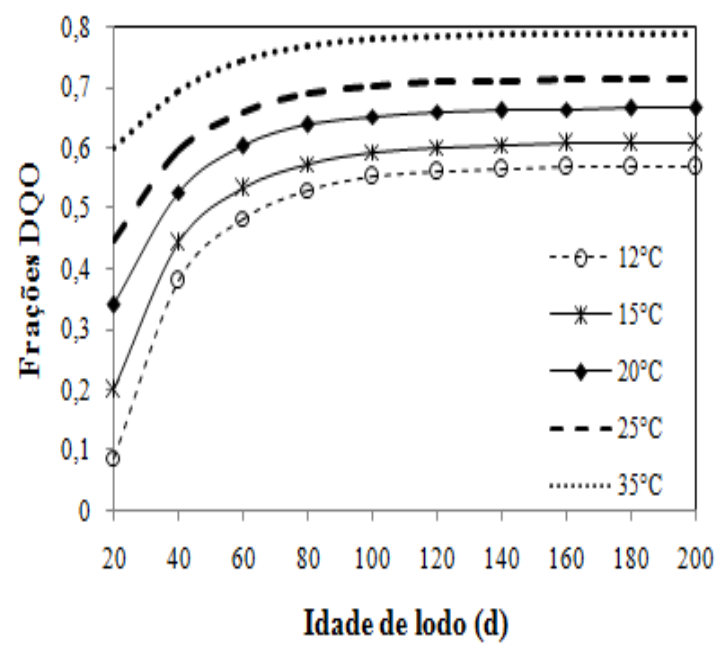

Figura 2 - Relação entre a eficiência máxima e a temperatura num reator UASB.

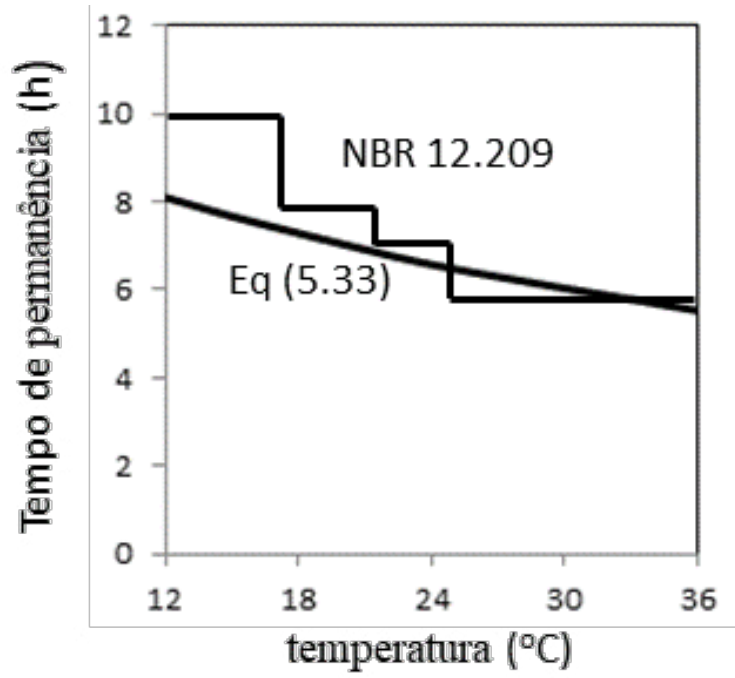

Figura 3 - Tempo de permanência necessário para eficiência máxima num reator UASB em função da temperatura segundo Santos, Chaves e van Haandel (2018) e NBR 12.209/2011.

Para diminuir tanto as desvantagens do sistema de lodo ativado como as do reator UASB, na prática se aplicam bastante os sistemas anaeróbio-aeróbio, como mostra a Fig. 4. Neste caso, grande parte dos SS e do MO é removida da fase líquida de modo que a carga orgânica sobre o sistema aeróbio de pós-tratamento é reduzida. O volume do sistema anaeróbio-aeróbio é em torno de $40 \%$ menor do que o sistema aeróbio. A possibilidade de gerar energia elétrica a partir do biogás pode ser um fator importante na redução de custos operacionais. Outra vantagem importante é que a estabilização de lodo de excesso da parte aeróbia do sistema pode ocorrer no próprio reator UASB, evitando-se o adensador e o digestor de lodo, que são parte do sistema puramente aeróbio. Todavia, Silva e van Haandel (2013) mostraram que a estabilização do lodo de excesso aeróbio no reator UASB somente é viável se houver uma unidade intermediária que retenha os sólidos no efluente do reator UASB. 


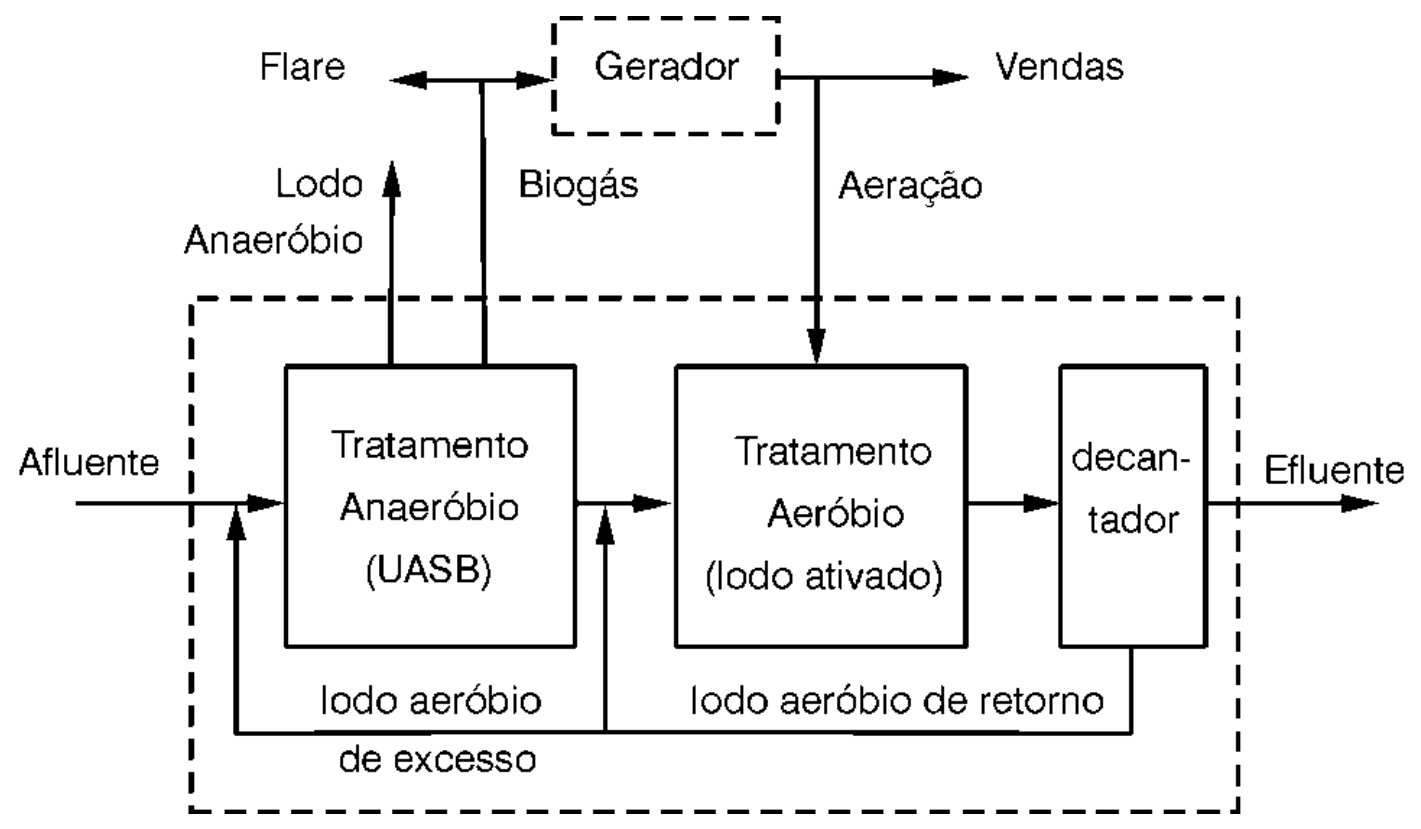

Figura 4 - Fluxograma de um sistema anaeróbio-aeróbio de tratamento

Um grande problema do sistema anaeróbioaeróbio é que a remoção dos nutrientes não é viável: a remoção eficiente do $\mathrm{MO}$ no reator UASB inviabiliza a remoção de nitrogênio por desnitrificação e de fósforo por incorporação no lodo, biodesfosfatação. Nesses casos, o nitrogênio pode ser removido pelo processo de desnitrificação autotrófica, que em sua forma mais simples pode ser expressa como (Mulder et al, 1995):

$\mathrm{NH}_{4}^{+}+\mathrm{NO}_{2}^{-} \rightarrow \mathrm{N}_{2}+2 \mathrm{H}_{2} \mathrm{O}$

Nesse processo, que usa bactérias específicas, as bactérias Anammox, não há necessidade de material orgânico para reduzir o nitrogênio para nitrogênio molecular. Contudo, o problema consiste no fato de que, sob essas condições a nitrificação deve ser parcial, ou seja, de amônia para nitrito, e não para nitrato.

A remoção de fósforo pela precipitação com íons metálicos pode ser considerada. Íons metálicos de sais de baixa solubilidade como $\mathrm{FePO}_{4}, \mathrm{AlPO}_{4}$ são usados, o que requer a adição de cátions
$\mathrm{Fe}^{3+}$ ou $\mathrm{Al}^{3+}$, geralmente na forma de $\mathrm{FeCl}_{3}$ ou $\mathrm{Al}_{2}\left(\mathrm{SO}_{4}\right)_{3}$. A precipitação de estruvita a um valor de $\mathrm{pH}$ de $8-8,5$ resulta num produto que pode ser vendido como fertilizante na agricultura. A reação prossegue conforme a equação mostrada abaixo (Ye et al, 2014):

$\mathrm{Mg}^{2+}+\mathrm{NH}_{4}^{+}+\mathrm{PO}_{4}^{3-}+6 \mathrm{H}_{2} \mathrm{O} \rightarrow \mathrm{Mg}\left(\mathrm{NH}_{4}\right)$ $\left(\mathrm{PO}_{4}\right) \cdot 6 \mathrm{H}_{2} \mathrm{O} \downarrow$

$\mathrm{MgCl}_{2}$ ou $\mathrm{MgO}$ podem ser usados para suprir um eventual déficit em magnésio.

\subsection{Lagoas de estabilização}

O sistema de lagoas de estabilização é usado em torno de $50 \%$ para o tratamento de esgoto no Brasil (IBGE, 2008), sendo esses mais aplicados em cidades pequenas do que em cidades grandes. A configuração mais comumente empregada para sistemas de Lagoas de estabilização compõem é composta de três tipos de lagoas distintas: (1) Lagoas anaeróbias, que recebem 
o esgoto afluente e operam com um ambiente anaeróbio onde a digestão anaeróbia se desenvolve e transforma parte do MO em biogás. (2) Lagoas facultativas, que recebem o efluente da lagoa anaeróbia e operam ao menos parcialmente em ambiente aeróbio, devido à produção de oxigênio fotossintético pelas algas que nela crescem e (3) Lagoas de maturação que operam em ambiente predominantemente aeróbio e cujo objetivo principal é reduzir os patógenos. O ambiente parcialmente aeróbio na lagoa facultativa é necessário porque a remoção do $\mathrm{MO}$ pela digestão anaeróbia é lenta, depois da passagem na lagoa anaeróbia onde parte considerável é removida. Como a produção de oxigênio pelas algas é lenta, a área da lagoa fotossintética deve ser grande para que a produção de oxigênio seja suficiente para manter um ambiente parcialmente aeróbio, mesmo à noite, quando não há fotossíntese.

O maior problema das lagoas de estabilização é que a área necessária para sua implantação é elevada. 0 tempo de permanência necessário nos três tipos de lagoas depende das suas funções: eficiência de digestão anaeróbia na lagoa anaeróbia, manter um ambiente parcialmente aeróbio na lagoa facultativa e eliminação de CTT nas lagoas de maturação.

Van Haandel e Lettinga (1994) analisaram e apresentaram os dados de vários pesquisadores e estabeleceram uma relação empírica com base em dados experimentais, que normalmente são expressos em diminuição da DBO na lagoa (vide Fig. 5):

$E=1-2,4(T D H)-0,50$

Em que:

$E=$ eficiência de remoção de $M O\left(D B O ~ m g . L^{-1}\right)$ $\mathrm{TDH}=$ tempo de permanência hidráulica $(\mathrm{h})$

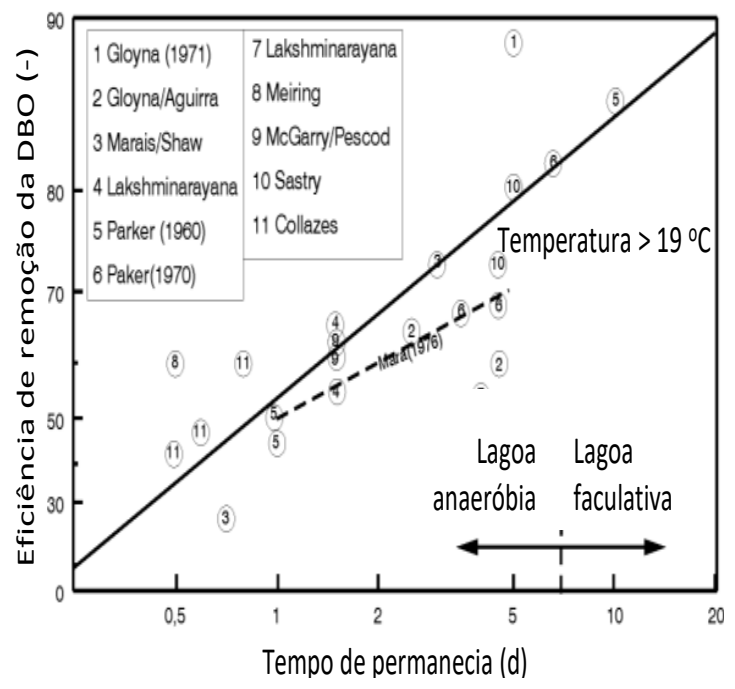

Figura 5 - Dados experimentais da eficiência de remoção da DBO em lagoas anaeróbias tratando esgoto bruto.

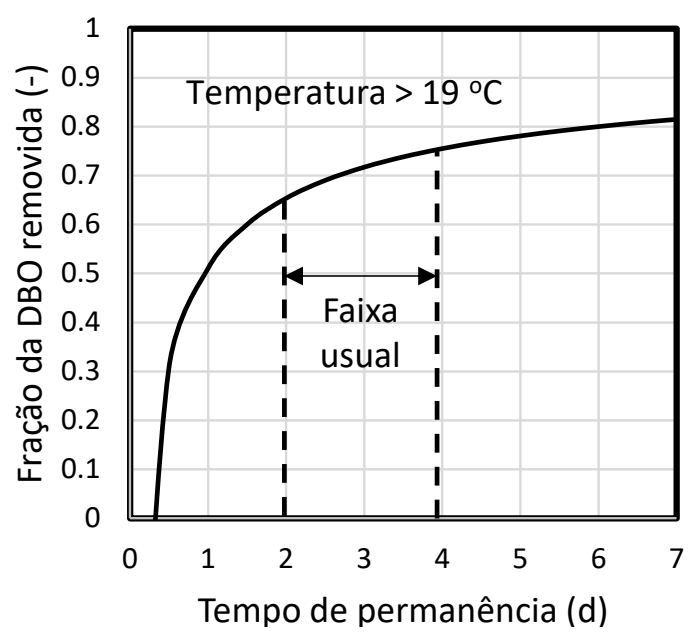

Figura 6 - Relação empírica entre a eficiência de remoção da DBO e o tempo de permanência em lagoas anaeróbias (temperatura $>19^{\circ} \mathrm{C}$ ).

A profundidade da lagoa anaeróbia é em torno de $4 \mathrm{~m}$, em parte em antecipação à acumulação de sólidos não biodegradáveis que se depositam no fundo da lagoa. Essa acumulação de sólidos resultará em um tempo de permanência efetiva menor na lagoa anaeróbia, com a consequente diminuição da eficiência de remoção da DBO. A relação empírica apresentada na Fig. 6 mostra que o aumento da eficiência de remoção da DBO é baixa para tempos de permanência de $4 \mathrm{~d}$ e, por 
essa razão, na prática uma lagoa anaeróbia usualmente tem um tempo de permanência de 2 a $4 \mathrm{~d}$. com uma eficiência de remoção da DBO em torno de 70\%. Essa remoção é considerável, mas de todo modo deixa em torno de $30 \%$ para ser removida na lagoa de polimento.

Depois da remoção parcial de MO na lagoa anaeróbia, a concentração de DBO na lagoa facultativa subsequente é baixa e, por isso, a taxa de digestão anaeróbia nessa lagoa é baixa. Por essa razão, a lagoa facultativa é operada em um ambiente ao menos parcialmente aeróbio, uma vez que as bactérias aeróbias removem MO mais eficientemente do que os micro-organismos anaeróbios quando a concentração é baixa. 0 oxigênio para o ambiente aeróbio é gerado na própria lagoa de maturação por algas, num processo de fotossíntese. Esse processo é lento e, portanto, requer um tempo de permanência longo. A manutenção de um equilíbrio entre a produção de oxigênio por fotossíntese e o consumo de oxigênio por bactérias no metabolismo de MO é a essência de projetos de lagoas facultativas. Ho et al. (2017) relatam mais do que uma dezena de equações empíricas que levam em consideração diferentes aspectos do tratamento em lagoas, mas que têm pouca utilidade para definir o tempo de permanência em um determinado caso de projeto em particular. No Brasil, lagoas facultativas são projetadas com um tempo de permanência em torno de 2 semanas e com uma profundidade de 1 a 1,2 m (MARA, 1976). Isso significa uma área de 1,4 $\mathrm{m}_{2}$ /habitante se a contribuição per capita é de 100 L/d.

O principal objetivo da operação de lagoas de maturação é a remoção de patógenos, particularmente os CTT, que são o grupo de bactérias mais ao decaimento em lagoas. Marais e Shaw (1961) estabeleceram que a diminuição da concentração de bactérias em lagoas é um processo de primeira ordem, independentemente da natureza do ambiente (anaeróbio ou aeróbio):
$\mathrm{dN} / \mathrm{dt}=-\mathrm{k}_{\mathrm{d}} \mathrm{N}$

A Eq. 2 pode ser usada para expressar a diminuição da concentração de CTT em lagoas de mistura completa:

$N_{e} / N_{i}=1 /\left(1+k_{d} T D H\right)$

Para uma série de lagoas de igual tamanho a expressão é:

$N_{e} / N_{i}=1 /\left(1+k_{d} T D H T / M\right)^{M}$

Normalmente a concentração de CTT é da ordem de $10^{7}$ a $10^{8}$ UFC/100 mL (UFC = unidades de formação de colônias). A concentração máxima para irrigação sem restrições é $10^{3} \mathrm{UFC} / 100 \mathrm{~mL}$ (OMS, 2006), de modo que se deseja uma diminuição de $10^{7}$ para $10^{3}$, ou seja, de 99,9 a $99,99 \%$ das bactérias devem ser removidas. Levando em consideração a remoção nas lagoas anaeróbia e facultativa tem-se:

$$
\begin{aligned}
& \mathrm{N}_{\mathrm{e}} / \mathrm{N}_{\mathrm{li}}=1 /\left(1+\mathrm{k}_{\mathrm{d}} \text { TDHla }\right)+1 /\left(1+\mathrm{k}_{\mathrm{d}} \text { TDH }_{\mathrm{ff}}\right)+ \\
& 1 /\left(1+\mathrm{k}_{\mathrm{d}} \text { TDH } / M\right)^{\mathrm{M}}
\end{aligned}
$$

Batista et al. (2021) estabeleceram que o valor da constante de decaimento depende da temperatura e da profundidade da lagoa e propuseram a seguinte expressão:

$k_{d}=(1,14 / H) 1,07^{(t-20)}$

Assim, é possível calcular que a remoção dos coliformes para $\mathrm{TDH}_{\mathrm{la}}=3 \mathrm{~d}$ numa lagoa anaeróbia com profundidade de $\mathrm{H}=4 \mathrm{~m}$ e operando a $25^{\circ} \mathrm{C}$ será $\mathrm{N}_{\mathrm{la}}$ / $\mathrm{N}_{\mathrm{i}}=1 /\left(1+\left(1 \cdot 14 / 4 * 1 \cdot 07^{(25-20) * 3))}=0,45\right.\right.$ e uma $\mathrm{N}_{\mathrm{lf}} / \mathrm{N}_{\mathrm{la}}=$ 0,042 de modo que a concentração residual nas primeiras duas primeiras lagoas é $\mathrm{N}_{1 f} / \mathrm{N}_{\mathrm{i}}=0,45^{*} 0,042$ $=0,02$. Portanto, para obter uma concentração de coliformes final, a remoção não pode ser menor que $\mathrm{N}_{\mathrm{e}} / \mathrm{N}_{\text {If }}=10^{3} /\left(0,02^{*} 10^{7}\right)=5^{*} 10^{-3}$, ou seja, nas lagoas de maturação devem ser removidos $99,5 \%$ dos coliformes. Na Fig. 7 pode-se observar a relação entre fração residual de coliformes e o tempo de permanência. Assim, por exemplo, para uma remoção de 99,5\% dos coliformes em duas lagoas em série o TDH $=17$ 
d, aproximadamente e para quatro lagoas em série $\mathrm{TDH}=7,5 \mathrm{~d}$. A eficiência desejada numa lagoa unitária de maturação só pode ser alcançada para um tempo de permanência muito longo, o que é impraticável, ainda que na prática haja muitos sistemas com essa configuração.

Os cálculos acima mostram dois fatos que merecem destaque (Batista et al., 2021):

(1) É importante ter uma subdivisão da lagoa de maturação para ter um número considerável de lagoas em série. Naturalmente, na prática, há um máximo no número de lagoas de maturação em série. Muitas lagoas de maturação se tornam contraprodutivas porque os taludes que separam as lagoas ocupam uma área maior na medida em que há mais lagoas. Na prática, sistemas de lagoas muitas vezes têm 3 ou 4 lagoas de maturação.

(2) O tempo de permanência em lagoas de maturação é considerável, da mesma ordem de grandeza da lagoa de polimento.

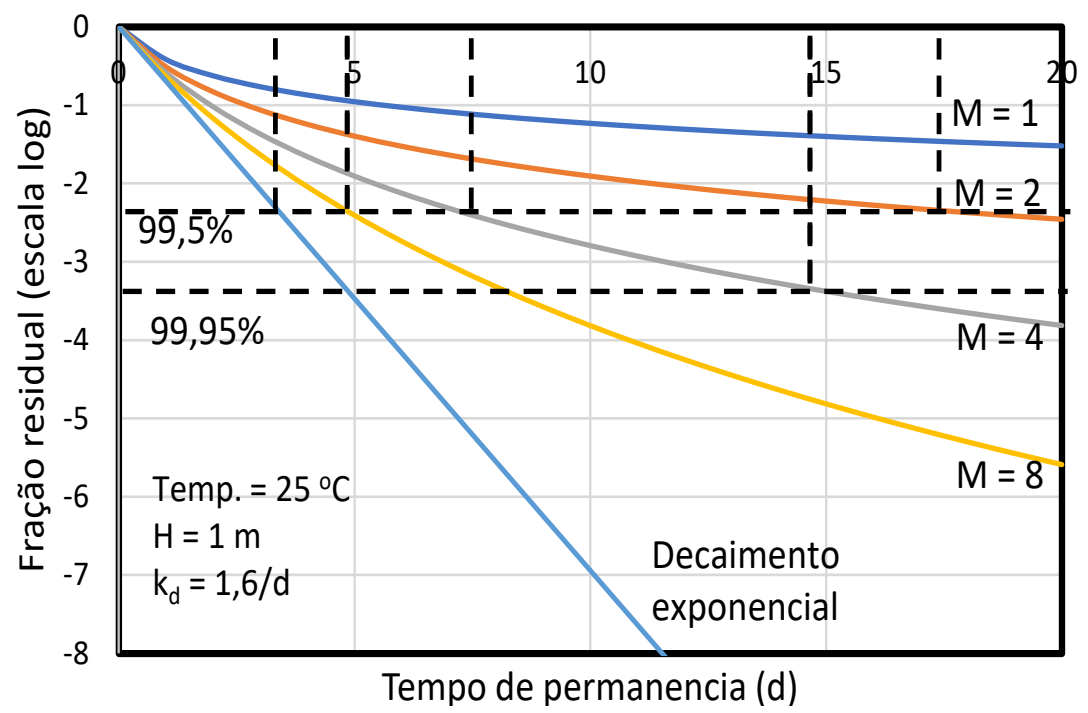

Figura 7 - Fração residual de CTT em função do tempo de permanência para diferentes séries de lagoas de maturação e para uma lagoa unitária operada em regime de bateladas.

Portanto, uma estimativa do tempo de permanência total é: Lagoa anaeróbia: 2 a 4d; Lagoa facultativa: $14 \mathrm{~d}$; e Lagoa de maturação: $14 \mathrm{~d}$, perfazendo um total de aproximadamente $30 \mathrm{~d}$. Quando se adota uma contribuição per capita de $0,1 \mathrm{~m}^{3} / \mathrm{d}$, isso significa um volume de $3 \mathrm{~m}^{3}$ por habitante. A profundidade média no sistema de lagoas de estabilização é de aproximadamente $1 \mathrm{~m}$, de modo que a área é de $3 \mathrm{~m}^{2}$ por habitante. A estrutura de sistemas de lagoas de estabilização leva a vários problemas na construção e na operação.
Os principais problemas de construção são:

(a) Devido ao longo tempo de permanência, há bastante evaporação de água que se pode estimar como se segue: com uma profundidade de $1 \mathrm{~m}$ e um tempo de permanência de $30 \mathrm{~d}$, a taxa de escoamento superficial é de $1 / 30=0,03 \mathrm{~m} / \mathrm{d}=$ $30 \mathrm{~mm} / \mathrm{d}$ e a taxa de evaporação geralmente tende a um valor entre 2 e $6 \mathrm{~mm} / \mathrm{d}$.

(b) Como a lagoa de estabilização é um sistema de fluxo contínuo, onde o esgoto percorre sequencialmente as diferentes lagoas, estas devem 
ter o mesmo nível, o que requer grandes escavações para aplanar a base das lagoas, especialmente em terrenos acidentados.

(c) Normalmente só há um sistema de lagoas de estabilização numa cidade, e esse sistema deve ficar afastado da região urbana por causa de maus odores que emanam da lagoa anaeróbia, o que requer investimentos vultosos na construção de um emissário longo. Muitas vezes o custo do emissário é maior que o custo das lagoas.

Os problemas operacionais são:

(d) Como o critério do projeto de lagoas facultativas é que haja equilíbrio entre produção e consumo de oxigênio, e também, entre consumo e produção de dióxido de carbono, o pH na lagoa facultativa se mantém constante na faixa neutra, o que inviabiliza a remoção de nutrientes.

(e) O biogás produzido no sistema causa maus odores ao ser liberado, além de tornar a lagoa de estabilização o sistema que mais emite gases de efeito estufa, uma vez que a emissão de metano contribui 21 vezes mais que dióxido de carbono. Esse fato torna o sistema de lagoas de estabilização o maior contribuinte de gases do efeito estufa.

(f) A geração de maus odores na lagoa anaeróbia é uma das razões da impopularidade do sistema com a população contribuinte.

(g) A lagoa anaeróbia deve ser interrompida com uma frequência de alguns anos para remover os sólidos acumulados. Por essa razão, normalmente se constrói mais que uma lagoa anaeróbia. Quando não se faz a operação de remoção dos sólidos acumulados com o tempo, a lagoa anaeróbia gradualmente perde sua função de digestor anaeróbio de $\mathrm{MO}$ e consequentemente todo o sistema terá um desempenho insatisfatório.

(h) Se o gotejamento for usado como método de irrigação, a presença de algas pode causar entu- pimentos nos orifícios de distribuição da água, por isso elas devem ser idealmente removidas.

\subsection{Um sistema inovador de tratamento: a combinação reator UASB + lagoas de polimento.}

Um sistema inovador de tratamento de esgoto foi desenvolvido visando eliminar os problemas inerentes ao sistema de lagoas de estabilização. No sistema convencional de lagoas de estabilização, a área é grande por duas razões: (1) a lagoa facultativa é grande porque é necessário manter um equilíbrio entre produção e consumo de oxigênio, e (2) as lagoas de maturação são grandes porque o decaimento de CTT é lento em reatores de fluxo contínuo. Assim, propõem-se as seguintes modificações: (1) A substituição da combinação lagoa anaeróbia + lagoa facultativa por um reator UASB e (2) a substituição da lagoa de maturação por lagoas de polimento, operadas em regime de bateladas sequenciais.

Sabe-se que o reator UASB é mais eficiente do que a combinação anaeróbia + lagoa facultativa e que seu efluente é mais transparente porque remove grande parte dos coloides (VAN HAANDEL e LETTINGA, 1994). Assim, seu uso não somente diminui o consumo de oxigênio devido à menor concentração de $\mathrm{MO}$, mas também aumenta a produção de oxigênio, devido à maior transparência do seu efluente. Também a substituição repercute em outras importantes vantagens:

(1) O problema de geração de odores é reduzido ou eliminado. $\mathrm{O}$ biogás produzido é capturado e pode ser queimado ou mesmo utilizado para geração de energia elétrica se a produção for suficiente.

(2) A produção de lodo pode ser descarregada em intervalos regulares em leitos de secagem para sua aplicação posterior como adubo, evitando interrupções da operação.

(3) Como a geração de odores e sua liberação à atmosfera é limitada ou inexistente, pode-se 
construir o sistema perto da região urbana ou mesmo dentro dela, evitando-se os custos de um emissário longo.

A descarga do efluente clarificado e de baixa concentração de MO do reator UASB garante que a fotossíntese predomine sobre a oxidação e o oxigênio dissolvido estará disponível na lagoa de polimento, receptora do efluente. Nessas condições é possível operar a lagoa em regime de bateladas sequenciais. Essa modificação traz importantes mudanças, principalmente no que se refere ao decaimento de CTT e viabilidade de remoção de nutrientes.

(1) Se a remoção de nutrientes não é necessária, o tempo de permanência é determinado pelo tempo de decaimento dos CTT, que é muito mais curto do que em lagoas de fluxo contínuo devido à cinética de primeira ordem do decaimento.

(2) Pelo fato de em lagoas de polimento a geração de oxigênio pela fotossíntese predominar sobre o consumo por oxidação de MO, há aumento do pH na lagoa que abre a de remoção de nutrientes; nitrogênio por dessorção de amônia gasosa e fósforo por precipitação de hidroxiapatita de cálcio.

No caso do decaimento de uma batelada de efluente, pode-se resolver a equação diferencial da Eq. 2 como:

$N_{e} / N_{i}=\exp \left(-k_{d} t\right)$

A Fig. 7 mostra o decaimento exponencial dos CTT em função do tempo. Pode-se observar que a fração residual dos coliformes em qualquer momento é muito menor do que em lagoas operadas em regime contínuo, e a diferença aumenta na medida em que se deseja uma eficiência maior. Assim, para a remoção de $99,5 \%$ dos CTT, precisa-se de 3 dias numa lagoa em regime de bateladas e de 7,5 dias numa séria de 4 lagoas de fluxo contínuo, tendo-se, portanto, uma proporção de 3/7,5 =0,4. Para uma remoção de $99,95 \%$, os tempos são 5 dias na lagoa de decaimento exponencial e de 15 dias na série de 4 lagoas de fluxo contínuo, tendose, portanto, uma proporção de 5/15 = 0,33.

Se o objetivo das lagoas de polimento é remoção de nitrogênio, a situação é diferente. Albuquerque et al. (2021) mostram que o aumento do pH é bem mais rápido em lagoas de bateladas sequenciais do que em lagoas de fluxo contínuo. Assim, se a remoção de nutrientes for o objetivo do tratamento lagoas em regime de bateladas também permitem uma redução de área importante. Nas Fig. $8 a$ e $8 b$ observa-se a porcentagem de remoção de nitrogênio em função do tempo de permanência para lagoas de fluxo contínuo (8a) e para bateladas sequenciais (8b) e para profundidades de 0,2 e $0,4 \mathrm{~m}$. As figuras mostram que para uma alta porcentagem de remoção (90\%) na LPBS o tempo de permanência é $8 \mathrm{~d}$, enquanto nas lagoas de fluxo contínuo um tempo de permanência um tempo de permanecia de 15 d é necessário. Portanto, o tempo de permanência e o volume nas LPFC são quase duas vezes maiores do que nas LPBS. Ainda assim, parece valer a pena a operação das lagoas em regime de bateladas sequenciais.

A diferença entre LPBS e LPFC é ainda mais pronunciada quando a remoção de fósforo também é o objetivo do tratamento, como mostram as Fig. 9 a e 9b. Pode-se observar que uma remoção eficiente é possível em 10 dias para uma profundidade de 0,4 m em LPBS. Em contraste, a remoção em LPFC é somente parcial: o pH nessas lagoas não aumenta suficientemente para provocar precipitação eficiente de hidroxiapatita.

A Fig. 10a mostra o fluxograma do sistema UASB-LPBS para a produção de água no reúso agrícola, quando se removem o material orgânico e os patógenos, mas não os nutrientes que podem ser aproveitados para aumentar a produção agrícola. $O$ tempo de permanência nas lagoas de polimento deve ser suficiente para efetuar o decaimento desejado dos CTT. 


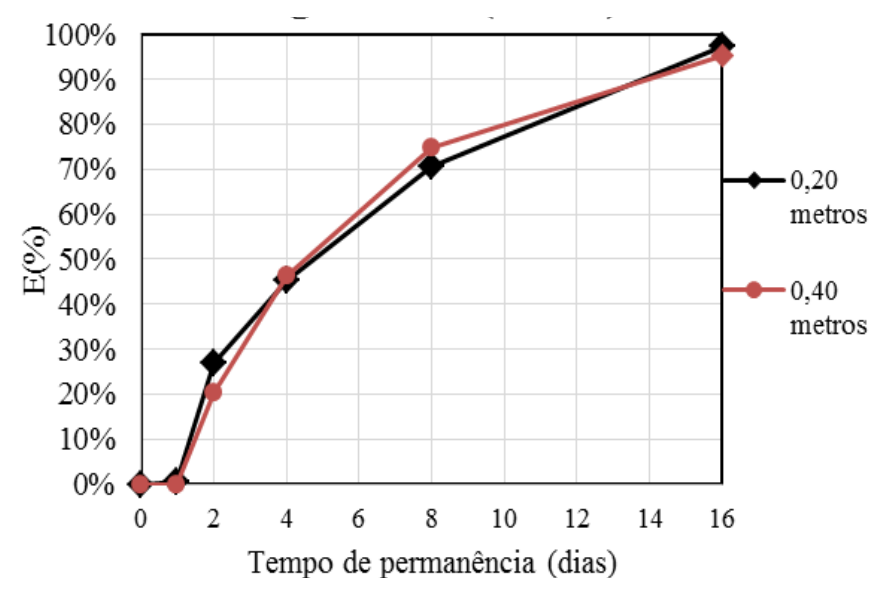

Figura 8a - Porcentagem de remoção de nitrogênio em função do tempo de permanência em lagoas de polimento de fluxo contínuo (LPFC) Profundidade 0,2 e 0,4 m.

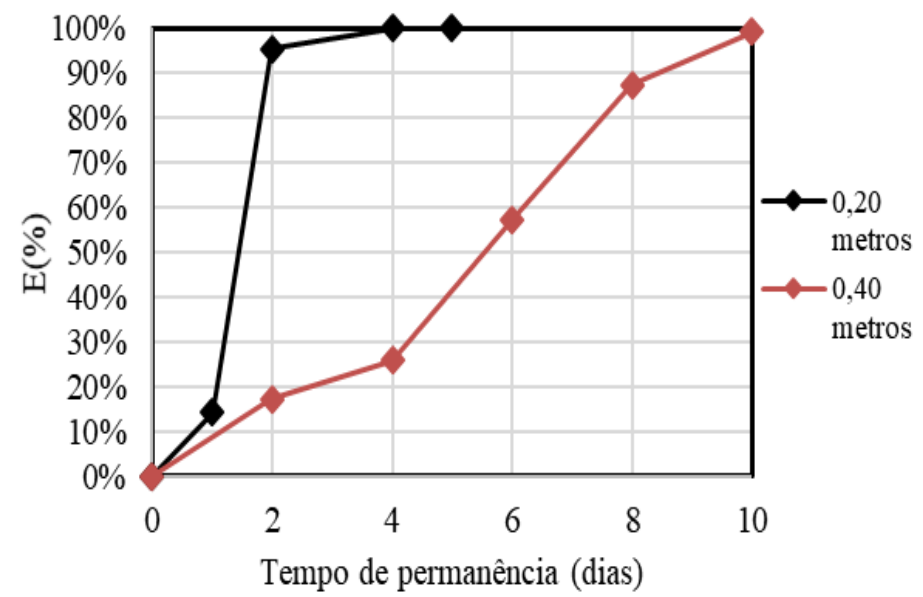

Figura $\mathbf{8 b}$ - Porcentagem de remoção de nitrogênio em função do tempo de permanência em lagoas de polimento de bateladas sequenciais (LPBS) Profundidade 0,2 e 0,4 m.

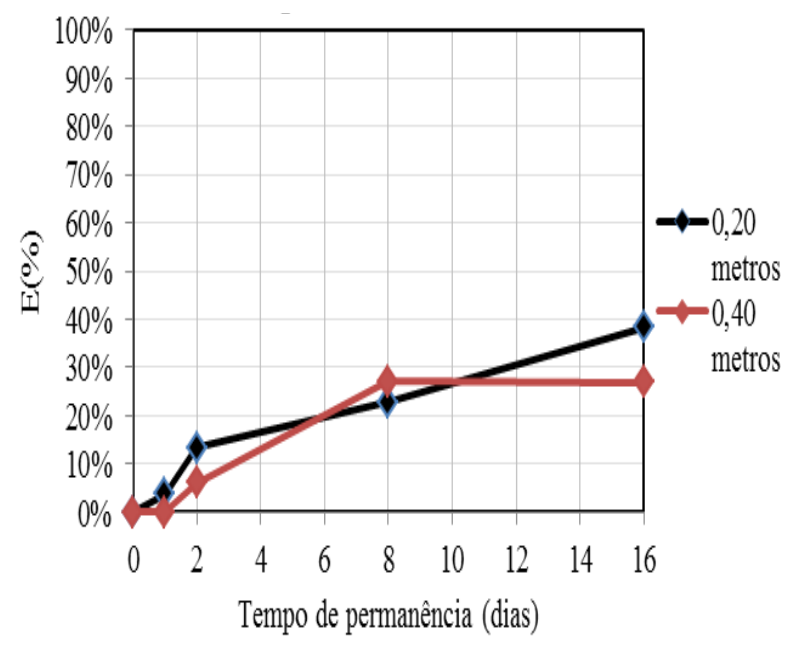

Figura 9a - Porcentagem de remoção de fósforo em função do tempo de permanência em lagoas de polimento de fluxo contínuo (LPFC). 


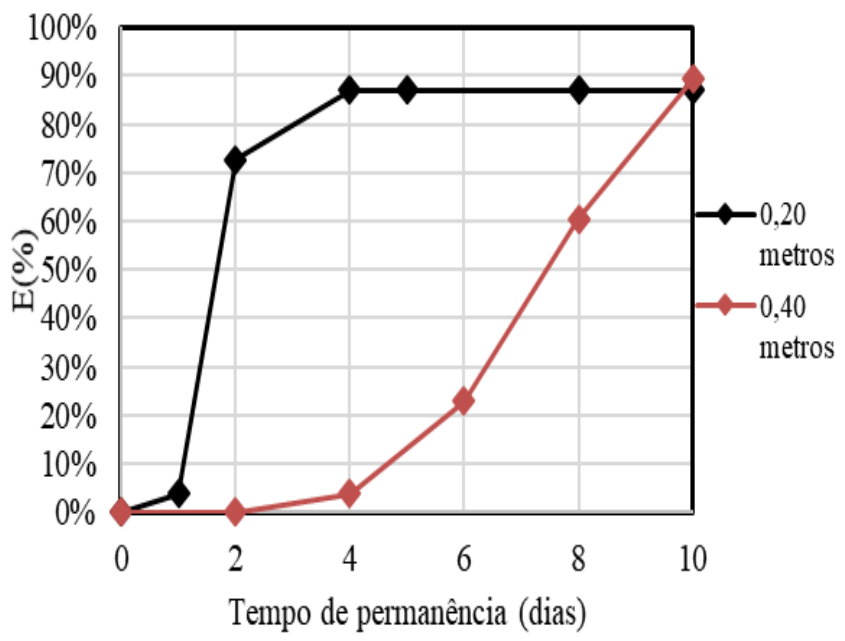

Figura 9b - Porcentagem de remoção de fósforo em função do tempo de permanência em lagoas de polimento de bateladas sequenciais (LPBS).

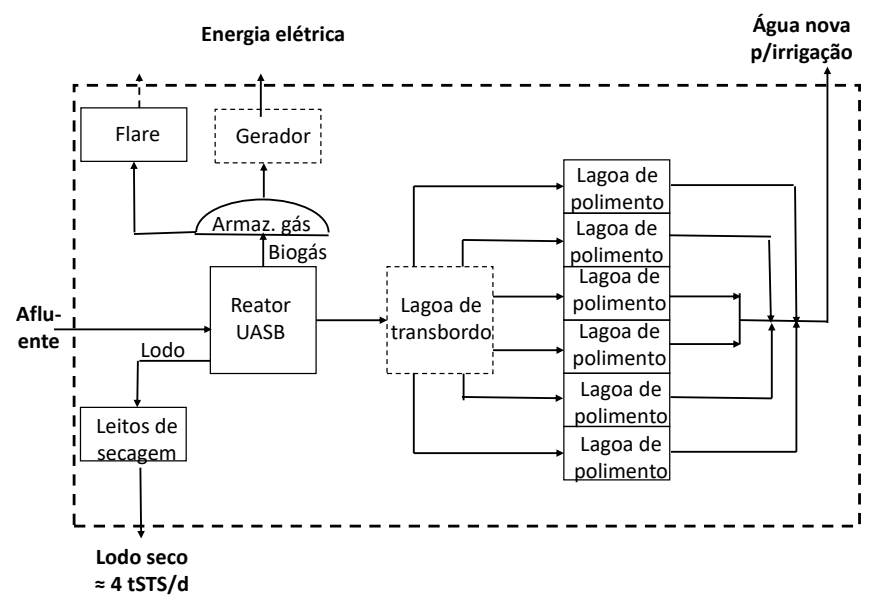

\section{Condições operacionais}

Profundidade: $0,5 \mathrm{~m}$

Tempo de permanência: $7 \mathrm{~d}$

Uso do efluente:

Irrigação sem restrições

Hidroponia

Aquacultura

Jardinagem, irrigação de parques

Lavagens de piso e de ruas

Figura 10a - Fluxograma do sistema UASB-LPBS para a produção de um efluente com nutrientes

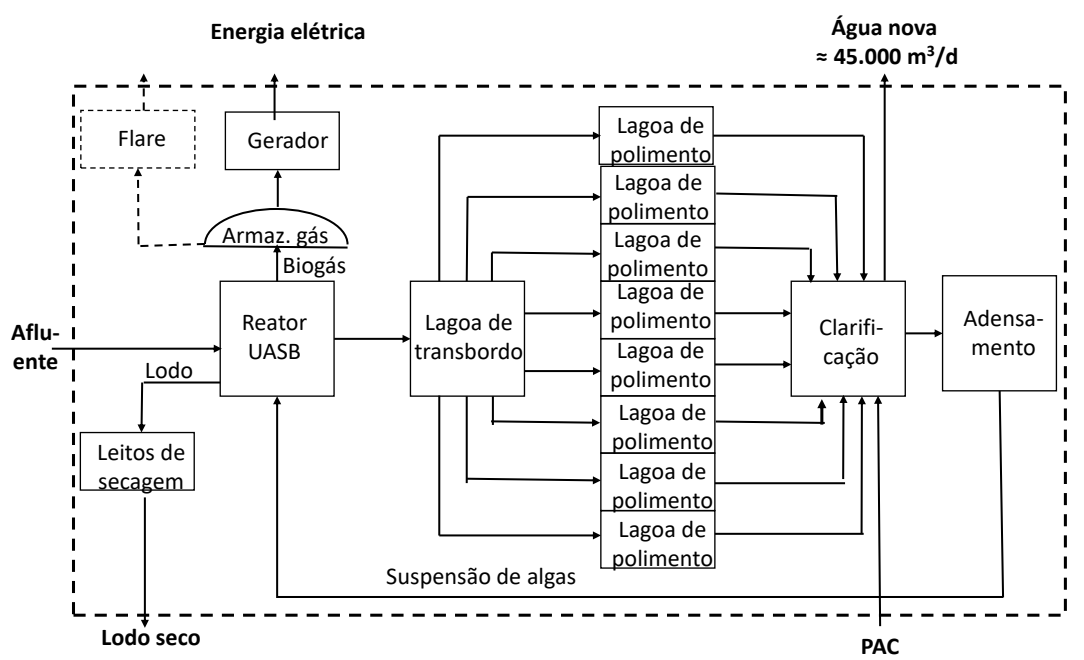

\section{Condições operacionais}

Profundidade: $0,5 \mathrm{~m}$

Tempo de permanência: $15 \mathrm{~d}$ para

dessorção de $\mathrm{N}$ e clarificação

\section{Uso do efluente:}

Indústria

Recreação (inclusive de contato primário)

Ambiental, recarga de aquífero, combater eutrofização Abastecimento público após tratamento avançado: osmose inversa

Figura 10b - Fluxograma do sistema UASB-LPBS para a produção de um efluente sem nutrientes 
A Fig. 10b mostra o fluxograma do mesmo sistema quando os nutrientes também são removidos. Nessa figura considera-se que na prática o efluente sem nutrientes em geral será usado para atender à demanda de água para indústrias, e nesse caso será necessário que a água esteja também livre de sólidos suspensos, mas o efluente tratado nas lagoas tem de 100 a 150 mg/L de SS, principalmente na forma de algas. A clarificação (coagulação + floculação + sedimentação + filtração) pode ser usada para remover os SS. O coagulante usado nesses processos também precipita o fosfato, de maneira que o aumento do $\mathrm{pH}$ por fotossíntese precisa somente atingir o valor para remoção de nitrogênio, que é 8,5-9,0. A remoção de fósforo em lagoas é quase completa a um $\mathrm{pH}$ de 9,5 a 9,7 em águas moderadamente duras $\left(\mathrm{Ca}^{2+} \approx 1 \mathrm{mmol} / \mathrm{L}\right)$, mas o tempo necessário para atingir é o dobro do tempo para atingir um $\mathrm{pH}$ de 8,5-9 necessário para remoção de nitrogênio.

Na Fig. 10b pressupõe-se que o fósforo será removido por clarificação. Geralmente o tratamento avançado como clarificação somente será aplicado quando se prevê reúso industrial. A clarificação representa um investimento considerável (praticamente se constrói uma ETA), mas para reúso industrial a qualidade do efluente final é primor- dial. Naturalmente, o custo desse tratamento será considerável, mas em muitas regiões do interior do Nordeste a disponibilidade de recursos hídricos é tão precária que sua aplicação é necessária para viabilizar o desenvolvimento industrial.

Na Fig. 11 podem-se observar os resultados de pesquisas publicadas nesta série de artigos e que foram realizadas em Campina Grande. Na Fig. 11 estão plotados em função da profundidade das lagoas de polimento em regime de bateladas sequenciais, a área necessária para as quatro tarefas principais de lagoas de polimento: redução da concentração de (1) MO; (2) patógenos; (3) nitrogênio; e (4) fósforo. Pode-se observar que a área é relativamente pequena para a remoção de $\mathrm{MO}$ e patógenos, independentemente da profundidade. A área para remoção dos nutrientes é bem maior porque só ocorre quando o $\mathrm{pH}$ é elevado e o aumento do $\mathrm{pH}$ é um processo lento. Para remoção de $\mathrm{MO}$ e patógenos, a área é de 0,6 a $0,7 \mathrm{~m}^{2} /$ habitante, um fator de 4 a 5 vezes maior do que em lagoas convencionais de estabilização. A remoção de nitrogênio requer uma área cerca de duas vezes maior do que a área para remoção de somente CTT e MO, enquanto a área de remoção de fósforo é o dobro da área para remoção de nitrogênio.
Lagoas no verão paraibano

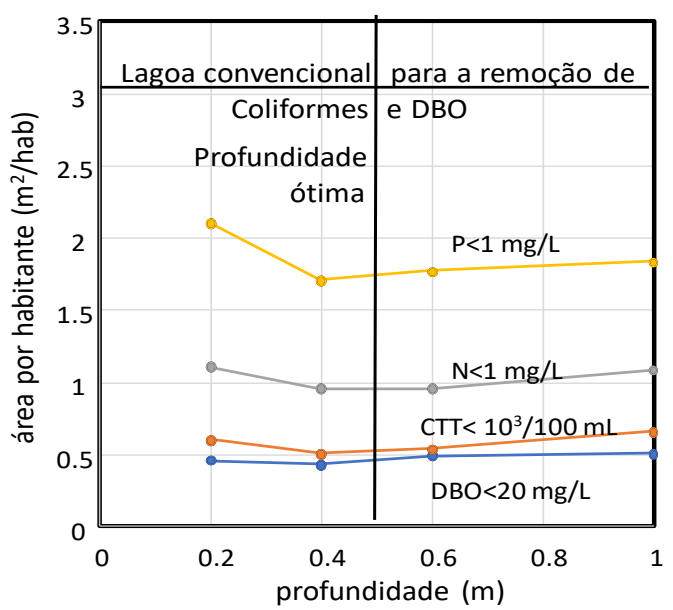

Lagoas no inverno paraibano

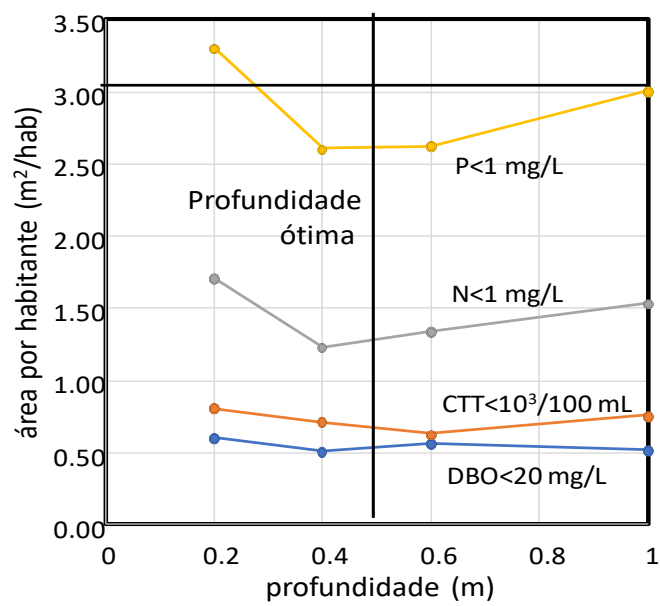

Figura 11 - Área per capita das LPBS em função da profundidade para remoção da DBO, dos CTT, de nitrogênio amoniacal e de fosfato, para as condições de verão e de inverno (per capita contribuição de 100 L.hab.d ${ }^{-1}$ ). 


\section{COMPARAÇÃO DOS SISTEMAS DE}

TRATAMENTO DE ESGOTO COM COMBINAÇÃO

REATOR UASB + LAGOAS DE POLIMENTO

Na comparação dos sistemas acima discutidos deve-se levar em consideração vários fatores, conforme apresentado na Tabela 3, sendo a qualidade do efluente o critério mais importante. A qualidade do efluente é definida pela eficiência de remoção dos constituintes indesejáveis: SS, MO, N, P, CTT e $\mathrm{OH}$, se a eficiência é suficiente para que o sistema possa produzir uma água que seja compatível com as exigências das normas ambientais. Ao analisar o item desempenho na Tabela 3, pode-se notar que o sistema UASB-LPBS produz a melhor qualidade de efluente, seguido por lodo ativado (com remoção de nutrientes), que podem, portanto, ser usados para todas as formas de reúso. $O$ efluente de lagoas de estabilização e de UASB-LPBS (sem remoção de nutrientes) pode ser utilizado para reúso agrícola e reúso urbano como jardinagem e lavagens em geral. O tratamento no reator UASB não pode produzir uma qualidade para que possa ser usado para reúso; a qualidade higiênica não permite. Na Fig. 12 é apresentada uma imagem que demostra a área relativa para cada tipo de sistema de tratamento de esgoto analisado.

Tabela 3 - Resumo dos principais sistemas de tratamento de esgoto

\begin{tabular}{|c|c|c|c|c|c|}
\hline \multirow{2}{*}{ Parâmetro } & \multirow{2}{*}{ Lodo ativado } & \multirow{2}{*}{ UASB } & \multirow{2}{*}{ Lagoa de estabilização } & \multicolumn{2}{|c|}{ UASB-LPBS } \\
\hline & & & & Efluente c/nutrientes & Efluente s/nutrientes \\
\hline \multicolumn{6}{|l|}{ Desempenho } \\
\hline DQOO & 90 & 80 & 80 & 80 & 90 \\
\hline STS & 90 & 20 & 20 & 20 & 90 \\
\hline Nitrogênio & 90 & 20 & 20 & 20 & 99 \\
\hline Fósforo & 90 & 20 & 20 & 20 & 90 \\
\hline Coliformes & 90 & 90 & 99,9 & 99,9 & 99,9 \\
\hline $\mathrm{OH}$ & 90 & 50 & 99 & 99 & 99,5 \\
\hline \multicolumn{6}{|l|}{ Tamanho } \\
\hline Área & 0,03 & 0,01 & 3 & 0,7 & 1,3 \\
\hline Profundidade & 4 & 4 & $4 / 1$ & $4 / 0,5$ & $4 / 0,5$ \\
\hline $\mathrm{TDH}$ & 1 & 0,25 & 30 & 7 & 13 \\
\hline \multicolumn{6}{|l|}{ Custo } \\
\hline Construção & Alto & Baixo & Variável & Baixo & Baixo \\
\hline Operação & Alto & Baixo & Baixo & Baixo & Baixo \\
\hline \multicolumn{6}{|l|}{ Simplicidade } \\
\hline Construção & Difícil & Simples & Simples & Simples & Simples \\
\hline Operação & Difícil & Simples & Simples & Simples & Simples \\
\hline Estabilidade Operacional & Instável & Estável & Estável & Estável & Estável \\
\hline Problemas & Disposição de lodo & Odores & Odores/Visibilidade & - & - \\
\hline
\end{tabular}

Figura 12 - Área relativa de diferentes sistemas de tratamento de esgoto. 
Outros fatores de grande importância são aspectos financeiros, simplicidade de construção e operação, bem como a estabilidade operacional. Ainda que o custo anual de construção do sistema mais caro (provavelmente o sistema de lodo ativado) seja menor do que o custo médio que o brasileiro (gasta com produtos cosméticos, por exemplo) consome (por equivalente de habitante), é importante que se reduzam os custos ao mínimo possível sem que se comprometa a qualidade da água produzida. Quanto à simplicidade de construção e de operação, os sistemas com pré-tratamento anaeróbio são preferíveis. $\mathrm{Na}$ construção se usa preferencialmente materiais locais e a operação é tão simples que pode ser realizada por pessoal não muito qualificado.

O sistema de lagoas de estabilização (LE) é ultrapassado por razões tecnológicas, ambientais, econômicas, sociais e estéticas. Comparado com o sistema UASB-LPBS, o sistema de Lagoas de estabilização ocupa uma área desnecessariamente grande, tem a maior produção de gases de efeito estufa de todas as alternativas de tratamento e prejudica a população com maus odores. Portanto, sua aplicação deve ser evitada.

\section{CONCLUSÕES}

(1) Idealmente sistemas de tratamento de esgoto devem ser projetados para reúso. Sistemas que preservem os nutrientes podem ser usados para aplicações agrícolas. Sistemas com remoção de nutrientes podem ser usados para qualquer forma de reúso.

(2) Em termos de desempenho, o sistema UASB-LPBS é superior aos outros sistemas de tratamento de esgoto apresentados quanto aos critérios analisados.

(3) As lagoas de polimento de bateladas sequenciais (LPBS) têm um desempenho superior ao das lagoas de fluxo contínuo (LPFC), tanto para sistemas sem como para sistemas com remoção de nutrientes.

(4) A área do sistema UASB-LPBS $\left(0,7 \mathrm{~m}^{2} / \mathrm{EH}\right)$ sem remoção de nutrientes é de 1,3 $\mathrm{m}^{2} / \mathrm{EH}$ com remoção de $\mathrm{N}$ e P, o que pode inviabilizar sua aplicação, especialmente em grandes centros urbanos.

(5) Sistemas de lodo ativado podem produzir um efluente de excelente qualidade, mas sua implementação pode esbarrar em problemas sérios de ordem financeira e de complexidade de construção e de operação.

(6) O sistema de lagoas de estabilização é inferior em vários aspectos quando comparado com o sistema UASB-LPBS, e sua aplicação é desaconselhável.

(7) $O$ reator UASB sem pós-tratamento é incapaz de produzir um efluente que possa ser usado para qualquer forma de reúso.

\section{AGRADECIMENTOS}

Os autores agradecem ao Conselho Nacional de Desenvolvimento Científico e Tecnológico (CNPq) pelo incentivo financeiro às pesquisas.

\section{CONTRIBUIÇÃO DOS AUTORES}

Todos os autores contribuíram de forma igualitária.

\section{REFERÊNCIAS}

ASSOCIAÇÃO BRASILEIRA DE NORMAS TÉCNICAS. NBR 12.209: Elaboração de projetos hidráulico-sanitários de estações de tratamento de esgotos sanitários. Rio de Janeiro, 2011.53p.

BATISTA, M. M.; LAMBAIS, G. R.; SANTOS, S. L.; VAN HAANDEL, A. Decaimento bacteriano em lagoas de polimento tratando efluente de reator UASB. Revista DAE: Edição especial, São Paulo, $n$. 229, março 2021.

BRASIL. Ministério do Meio Ambiente. CONAMA. Resolução $n^{\circ}$ 357, de 17 de março de 2005: Dispõe sobre a classificação dos corpos de água e diretrizes ambientais para o seu enquadramento, bem como estabelece as condições e padrões de lançamento 
de efluentes, e dá outras providências. Diário Oficial da União, Brasília, 2005.

BRASIL. Ministério do Meio Ambiente. CONAMA. Resolução $n^{\circ}$ 430, de 13 de maio de 2011: Dispõe sobre as condições e padrões de lançamento de efluentes, complementa e altera a Resolução no 357, de 17 de março de 2005, do Conselho Nacional do Meio Ambiente CONAMA. Diário Oficial da União, Brasília, 2011.

GUIDELINES FOR WATER REUSE. Water Recycling and Reuse: The Environmental Benefits. USEPA. Retrieved 29 July 2019.

INSTITUTO BRASILEIRO DE GEOGRAFIA E ESTATÍSTICA - IBGE. Pesquisa nacional de saneamento básico - 2008, 2010. Disponível em: < http://www.ibge.gov.br>. Acesso em: 20 fev. 2020.

HO, L. T.; ECHELPOEL, W. V.; GOETHALS, P. L. M. Design of waste stabilization pond systems: A review. Water Research, vol. 123, p. 236-248, 2017. https://doi.org/10.1016/j.watres.2017.06.071

MARA, D. D. Proposed design for oxidation ponds in hot climates. J. Environ. Eng. Division-Asce, v. 101, p. 296-300, 1976.

MARAIS, G.V.R.; SHAW, V.A. A rational theory for the design of sewage stabilization ponds in Central and South Africa. Transactions of the South African Institute of Civil Engineering, 3, 1961.

MULDER, A.; VAN DE GRAAF, A. A.; ROBERTSON, L. A.; KUENEN, J. $G$. Anaerobic ammonium oxidation discovered in a denitrifying fluidized bed reactor: FEMS. Microbiology letters, 16, pp. 177184, 1995.

SANTOS, S. L.; CHAVES, R. M. S.; VAN HAANDEL, A. Influence of temperature on the performance of anaerobic treatment systems of municipal wastewater. WATER S.A, v. 44, p. 211-222, 2018.

SILVA FILHO, J. A; VAN HAANDEL, A.C. Estabilização de lodo de pós-tratamento aeróbio na unidade de pré-tratamento. Revista DAE, p. 46-63, 2013.

VAN HAANDEL, A. C.; LETTINGA, G. Anaerobic sewage treatment: a practical guide for regions with a hot climate. John Wiley and Sons, 1994, 222p.

VAN HAANDEL, A. C.; MARAIS, G. 0 comportamento do sistema de lodo ativado: teoria e aplicações para projetos e operações. Campina Grande: epgraf, 1999. 472 p.

VAN HAANDEL, A.C.; VAN DER LUBBE, J. Anaerobic sewage digestion: Theory and applications. International Water Association Londres RU, 2019.

YE, Z. Y.; SHEN, Y.; YE, X. Phosphorus recovery from wastewater by struvite crystallization: Property of aggregates. Journal of Environmental Sciences. n. 26 (5), p. 991-1000, 2014. https://doi. org/10.1016/S1001-0742(13)60536-7 